\title{
Examining the Quality of Electronic Services and Its Relationship with User Satisfaction in Social Security Organization (Branch 17)
}

\author{
Shohreh Mohammadzadeh Agh Ghaleh
}

M.A from Department of Social Sciences Research, Roudehen Branch, Islamic Azad University, Roudehen, Iran

Dr. Khalil Mirzaei

Department of Social Sciences, Science and Research Branch, Islamic Azad University, Roudehen, Iran

Doi:10.5901/mjss.2016.v7n3s3p402

\begin{abstract}
Given the importance of service quality in service organizations, this article attempted to analyze the impact of perceived quality of electronic services on user satisfaction with the provided services. To do this end, a questionnaire was designed and implemented to measure the satisfaction level of electronic services provided by Social Security Organization. It should be noted that the mentioned questionnaire was based on diverse dimensions of quality of electronic services offered in the form of a conceptual model (including usability, information quality and service interaction). This research was a survey study and it made use of a random sampling method thereof. Having collected data from a sample of 250 users of electronic services of the Social Security Organization (Branch 17) as well as doing correlation and linear regression tests, it was indicated that the perceived quality of electronic services has had a statistically significant and positive impact on user satisfaction with these services.
\end{abstract}

Keywords: Electronic service quality, usability, information quality, service interaction, user satisfaction, Social Security Organization

\section{Introduction}

The bureaucratic mazes are among the major problems of developing countries and, thus, the quality of service provided to users does not receive much attention. Since our country is famous for being bureaucratic in nature, the subject of honoring customers has been repeatedly discussed in recent years and it has been a lot of publicity. In such a situation, many organizations argue that they have run electronic government throughout their own organizations. Accordingly, the question is whether the mere claim that we provide electronic services to our customers is enough. It seems that the logical approach is to review and assess these claims because a claim or even providing such services is not enough and that the quality of these services is important as well. Thus, how these services are offered and at what level and to what extent the objective is met, which is the user satisfaction, must receive due attention. In this regard, it is important to discover whether the electronic services provided by organizations to users have the desired quality or they can fulfill user satisfaction or not. Alternatively, governments may take advantage of information and communication technology and electronic government to improve and revitalize service quality. The main channel of providing electronic services is the organization's website through which all the services are provided. This is where the measurement of service quality goes beyond the organization's physical environment and building and it enters into the virtual world of websites. So, this major change in the way services are provided will lead to change in the manner of measurement and some new measurement indicators are required to assess and evaluate these types of services. As such, this article, which is derived from a systematic research, attempted to assess and evaluate the status of electronic services provided by the Social Security Organization and determined the extent to which users were satisfied with the service quality.

\section{Literature review}

\subsection{Service quality}

Service quality includes a comparison between expectations and performance. In other words, service quality is "the difference between customers' expectations and perceptions of received services" (Zeithaml, Valarie, Parasuraman and Malhotra, 2002). Alternatively, service quality is the extent of achieving a given service. In this regard, the quality of 
objective and subjective services can be identified as follow:

- The objective of service quality is to measure the tangible compliance of work results with the previously defined benefits. Since there is a significant interdependence between measurement and precision of definition, the criterion of quality measurement becomes subjective thereof.

- Subjective service quality is the compliance of work result with the expected benefits. This perception is the result of initial customer's perception of services and the tendency of service provider to represent premier performance.

- Although researchers have repeatedly investigated the concept of service quality over the last decades, there has been no convergence and agreement on the concept of service quality. The latter may be due to this fact that, until now, many researchers have focused on different aspects of service quality. All in all, the common ground of such research is that since these are intangible and homogenous services and the deployment of them is often separable, the process of evaluating the service quality is exceptionally combinatory in nature. As such, this process cannot be easily detected (Parasuraman, Zeithaml and Malhotra, 2005).

\subsection{Electronic service quality and its measurement}

Governments may take advantage of information and communication technology and electronic government to improve and revitalize service quality. The main channel of providing electronic services is the organization's website through which all the services are provided. This is where the measurement of service quality goes beyond the organization's physical environment and building and it enters into the virtual world of websites. So, this major change in the way services are provided will lead to change in the manner of measurement and some new measurement indicators are required to assess and evaluate these types of services.

The concept of quality is defined differently in business literature and it can be examined from different aspects. Regarding the viewpoint of producers, it may be argued that quality is the ability of a given product to accomplish those functions for which it is designed. Regarding the customer side, the quality refers to those features and characteristics of the product or service that affect its ability to create satisfaction among users. Formerly, the quality was considered synonymous to satisfaction and they were used interchangeably. However, it is presently believed that the two concepts are quite different in terms of meaning and measurement criteria. Satisfaction is a broader concept than quality and it may be argued that quality is among the factors that lead to customer satisfaction.

Customer satisfaction is to assess whether the product or service has been able to meet his/her needs and expectations or not (Iran Nejad Parizi, 2005). In fact, customer satisfaction is a response to his/her satisfaction and it represents a judgment about the features of a product or service or the nature of that product or service that indicates an optimal level of satisfaction associated with consumption (Shankar, Smith and Rangaswamy, 2003). The result of such a satisfaction may be represented in the form of customer loyalty, repurchase and recommending others to use the company's products and services (Zeithaml, Valarie, Parasuraman and Malhotra, 2002).

As mentioned, the quality (of services or products) is one of the factors that affect the user satisfaction and as the customer perception of the quality of the product or service increases, the level of customer satisfaction and loyalty and, thus, their possible purchase increases thereof. Previously, the majority of scientific studies in the field of quality have been focused on the quality of physical products. However, in recent decades, the concept of service quality has included such aspects as intangibility, inseparability, non-maintainability and heterogeneity. It should be noted that service quality has been the dominant and determining element in customer satisfaction.

\subsection{E-service quality measurement models}

One of the most important features of models on electronic service quality classification is that they are mainly focused on features of service quality, level of information provided, the manner and some features of the system. Another feature of these classifications is that they lead to such results that are derived from merger, adaptation and development of existing models. As mentioned, the main channel of providing electronic services is the organization's website through which all the services are provided. There are three types of situations in the field of electronic services that require evaluation. The first one is the electronic environment. The second one belongs to the realm of evaluation of performance of an electronic program or project. The third domain deals with the overall effect of electronic services on the overall performance of an institution, economic development and public services (Bhattacharya, Ecker, Olsson and Schipper, 2012a).

Regarding the academic research, there are some main models for measuring the quality of electronic services, as 
follows:

\subsubsection{Web-Qual Model}

Loiacono, Watson and Hoodhue (2002) made use of twelve original constructs to measure the process of development and validation of the quality of a website. They attempted to make use of "The Theory of Rational Action" and, thus, made use of information technology in the "Technology Acceptance Model". Thus, the "Technology Acceptance Model" has been adopted from "The Theory of Rational Action". The Theory of Rational Action makes use of different variables to predict the behavior of individuals in certain circumstances. According to this theory, the behavior of each individual stems from his/her intention and these intentions are also subordinate to his/her attitude and internal norms.

Having conducted some research, Loiacono, Watson and Hoodhue (2002) concluded that four aspects of usefulness, ease of use, attractiveness and friendly relations might be used to assess the quality of information services websites. Furthermore, the mentioned aspects included 12 indexes.

\subsubsection{Website Quality Model}

Website Quality Model (Zhang and Prybutok, 2005) is proposed for a set of qualitative factors in web design quality and it is divided into specific categories and features. As such, each of these features guides the formation of customers' expectations towards designing a website. Besides, these categories include information content, cognitive consequences, entertainment, privacy, user support, exhibitive appearance, technical support, guidance, organizing the information content, credibility and impartiality. There is a questionnaire through which each user evaluates (basis, performance or provocation) each assessed category. Although this model pays special attention to design and usability of website, other factors such as user interaction and website are also given due consideration. This model is used in various fields (electronic education, sale, etc.).

\subsubsection{E-Sequal Model}

E-Sequal is an assessment tool that merges strategies for managing customer relationship and human-computer interaction to design and evaluate electronic commerce situations. Furthermore, it aims to meet customers' expectations and provides optimal service quality as well as guidelines to protect not only the user in interaction with website during the process of electronic purchase, but also to establish connection at all points of possible contact between the user and electronic commerce and dealing with services. The model consists of a set of (initiated and subordinate to initiatives) requirements or solutions that remove or avoid those specific obstacles due to reduced customer perceptions of observed value. An obstacle is an aspect of electronic commerce environment which makes it tasteless, difficult, impossible or inadequate for users to achieve a positive overall experience (including such problems as accessibility, hidden costs, return of unclear information or information that is not readily available). The initiatives and subordinate initiatives are classified into the following three categories: initiatives prior to purchase (which are related to manner by which one decides to buy from a particular website), purchase initiatives (which are related to product or service selected by the customer in order to buy and check online) and initiatives after the purchase (after choosing a set of initiatives in dealing with services).

\subsubsection{E-Qual Model}

Having used the website, the expectations of the level of service provided by public sites will significantly increase. This model is founded on the basis of user perceptions of quality measured by its significance. Regarding this model, there are five determining factors of usability, design, information, trust and empathy which have been integrated into three factors of usability, information quality and service interaction. This model has been proposed by Barnes and Wyden to assess the quality of website. Furthermore, the model has been tested in many fields, including online bookstores, auction sites and electronic government. The E-Qual Model makes use of 23-item survey tool to solicit users' subjective perceptions. The analysis of survey data reveals that E-Qual represents the following three basic components: usability, information quality and service interaction. Besides, each of these components provides some specific conclusions for website provider.

- Usability consists of such items as "ease of exploration" and "ease of operation learning". This element points to the dire need for deployment of usability tests to the website (Rosson and Carroll, 2002). 
- Information quality (i.e., "credible information,"correct information" and "timely information"), requires organizations to adopt defined content management practices (Delon and Mack Lyon, 1993).

- The quality of service interaction deals with the manner in which an organization represents itself and accomplishes its work in a virtual world. An important factor in the service interaction is the concept of trust which is extracted from such item as "the importance of security of personal information". Therefore, the EQual Model is considered a comprehensive and verified framework to assess user perceptions of the quality of a website (Anderson and Srinivasan, 2003).

- The E-Qual is based on quality function deployment (QFD) and this is a structured and systematic process. Furthermore, this is a tool to identify and deliver the voice of the customer through each stage of development and application of a product or service. QFD may be applied via adopting a "user's voice" and identifying the quality requirements using some meaningful words for users. Then, the quality is reflected by the customer and the basis of a quality assessment is formed for a product or service.

- The E-Qual differs from those studies that emphasize on features or characteristics of the website. Regarding some studies conducted as part of subsequent processes in QFD in the context of E-Qual, the website users are asked to rank the desired sites against a set of qualitative norms and each qualitative norm is ranked in terms of importance. Although qualitative norms are designed subjectively in the context of E-Qual, there are not sufficient data analyses using quantitative techniques (i.e. running reliability tests for E-Qual tools).

\section{Customer Satisfaction Models}

\subsection{Kano Model}

The Japanese Professor, Noriaki Kano, is a renowned theorist in the field of world-class quality. He believes that the concept of quality is an integral part of any business and it is a key factor in global competition. Regarding the increasing scope of global competition, it seems that it is impossible to meet the needs of customers only through existing products. Accordingly, it requires producing and presenting some innovative and modern products to meet the customers' expectations and this depends on a detailed understanding of their changing needs and demands. Thus, the concept of quality is defined as follow: the quality points to responding to the needs, desires and expectations of the user (customer) and even going beyond his/her satisfaction.

\subsection{Electronic Customer Satisfaction Index (E-CSI)}

This model is based on three main antecedents of customer satisfaction (trust, electronic services and perceived value) and two consequences of customer satisfaction (customer complaints and loyalty). This model is derived from the ACSI model where customer expectations and service quality are replaced by customer loyalty and the quality of electronic services.

\section{Research background}

Molavi (2009) conducted a research titled "a survey of relationship between electronic service quality and electronic satisfaction in banking system; the case of central branch of Agricultural Bank" and proposed the Zeithaml Model in which the quality of electronic services was proposed as a 7-item phenomenon (efficiency, fulfillment, reliability, personal privacy, responsiveness, compensation and contact). Then, she measured their impact on customer satisfaction and concluded that there was a significant relationship between these seven items and customer satisfaction.

Golshani Mehr (2011) conducted a research titled "assessing the impact of electronic service quality and customer satisfaction on financial performance of Bank Saderat Iran". Having collected a sample of 187 customers of Bank Saderat Iran in some distinguished and first-class branches in Tehran and Alborz provinces, the subjects were asked to respond to electronic service quality and customer satisfaction. Given the first hypothesis, the analysis of the data showed that all dimensions of electronic service quality (except Internet Bank) have had significant impacts on customer satisfaction. Regarding the second hypothesis, it was indicated that only ATM service quality and perceived value have had significant positive effect on financial performance of Bank Saderat Iran. Results for the third hypothesis suggested that there was a significant positive relationship between customer satisfaction and financial performance of the Bank. The fourth hypothesis indicated that the ATM service quality and perceived value of services directly and indirectly (through 
customer satisfaction) influenced the financial performance of Bank Saderat Iran. Also, the quality of telephone banking services and the quality of basic services have only had indirect impact (through customer satisfaction) on the financial performance of Bank Saderat Iran.

Hejazi (2005) conducted a research titled "measurement of satisfaction in Ramak Company by fuzzy approach" and attempted to review, identify, measure and prioritize the factors affecting customer satisfaction with the Ramak Company. The results showed that the variables of ease of access, complaint resolution, quality and price have had a determining impact on customer satisfaction.

Molavi (2009) conducted a research titled "a survey of relationship between electronic services quality and electronic satisfaction in banking system; the case of central branch of Agricultural Bank of Tabriz" and concluded that there was a significant relationship between electronic service quality and its dimensions (efficiency, fulfillment, reliability, personal privacy, responsiveness, compensation and contact) and electronic customer satisfaction in the central branch of Agricultural Bank of Tabriz. Also, the quality of electronic services has had the most relevant connection with users' electronic satisfaction.

Zhang and Prybutok (2005) did a research titled "a consumer perspective of electronic service quality" and made use of such variables as individual differences, facilities of electronic services, the quality of website services, risk-taking, electronic satisfaction and intention to develop the model for electronic services. Regarding these factors, service facilities, service quality, website and risk-taking were among the most determining factors affecting the level of consumer satisfaction. Furthermore, ease of electronic services, perceived risk and website quality were ranked as factors affecting the customer satisfaction. In addition, it was indicated that there was a relationship between customer satisfaction and the decision to buy. Conversely, only the hypothesis on the relationship between individual abilities in using computer and the ease of use of electronic services was rejected. Finally, they concluded that the customer experience was associated with behavioral intentions and that as there was more positive customer experience, he/she would be more inclined to reuse the service.

\section{Conceptual frameworks and model}

There should be a theoretical framework, called the conceptual model, to conduct scientific and systematic research. The theoretical framework is a conceptual pattern which is based on a number of theoretical relations among some factors that are important in the field of research. This theoretical framework is rationally envisaged via examining the research records in the territory of research subject. Accordingly, the conceptual model in this study is as follow (Diagram 1).

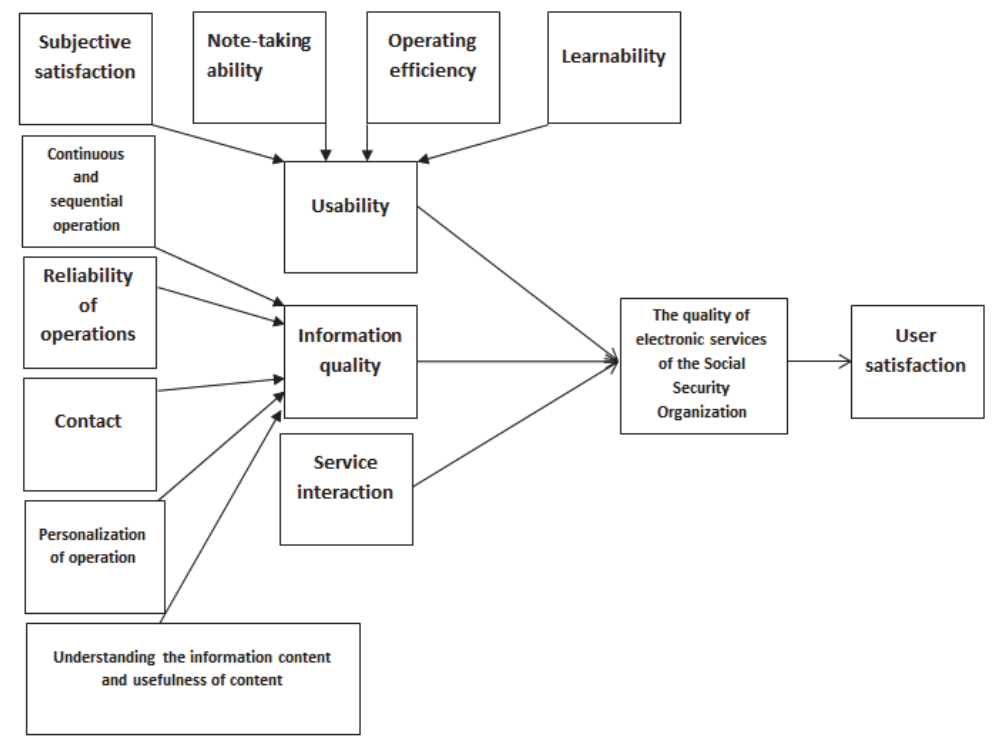

Diagram 1. The research conceptual model 


\section{The research hypothesis}

\subsection{The first hypothesis:}

There is a relationship between the usability of electronic services of the Social Security Organization and user satisfaction.

\subsection{The second hypothesis}

There is a relationship between the information quality of electronic services of the Social Security Organization and user satisfaction.

\subsection{The third hypothesis:}

There is a relationship between service interaction of the Social Security Organization and user satisfaction.

\section{Methodology}

Regarding the operational criterion, this study was an applied research because it was done in a real organization and it was used in real life. Given the temporal criterion, this study was of cross-sectional nature. Regarding the data collection method, this study was categorized as document and field studies because books, article, etc. were used to propose the theoretical framework and research background. Furthermore, questionnaires were used to collect the required data. Given that this research involved collecting information directly from a group of individuals and since the results of the sample would be generalized into the entire population, it could be argued that it was a survey study (Mirzayi, 2009).

A researcher-made questionnaire was used as a data collection tool to gather the desired data. The questionnaires were designed in the form of closed questions in the following two parts: the first part included questions about gender, age and level of education of the respondents and the second part consisted of 28 items about the quality of electronic services of the Social Security Organization and user satisfaction. Regarding the latter part, the respondents were asked to comment about any item by choosing one of the options of "strongly agree, agree, no idea, disagree and strongly disagree". As such, the Likert scale was used to measure the constructs. Regarding the grading scheme, it was decided to assign numbers 5 to 1 for the first option (strongly agree) to the last option (strongly disagree), respectively. Each of the variables was assessed using a number of items of questionnaire and the total score of items for each variable was determined to represent the score of each variable.

\subsection{Validity}

The content validity and CVR coefficient were used to ensure the quality of the research tool. Since the value of CVR coefficient was greater than the minimal level of 0.6 , it could be argued that all items had acceptable level of validity. The total CVR coefficient for all items was 20.8. To do this end, the mentioned total value was divided into total number of questions and, thus, the total value of CVR coefficient was obtained as 0.74 which indicated that the items of the questionnaire had an acceptable level of content validity.

\subsection{Reliability}

The internal consistency reliability (Cronbach's alpha) was independently used for each variable to ensure the stability of the measurement tool. The results of Cronbach's alpha for the quality of electronic services perceived by users and user satisfaction were 0.874 and 0.7 , respectively. Furthermore, the Cronbach's alpha for the total scale was 0.864 , which was an acceptable value. As the value of alpha moves closer to 1 , there will be more level of internal consistency.

Table 1. Cronbach's alpha

\begin{tabular}{|l|c|c|}
\hline Variable & Number of items & Cronbach's alpha \\
\hline The quality of perceived electronic services & 22 & 0.874 \\
\hline Satisfaction & 6 & 0.7 \\
\hline Total questionnaire & 28 & 0.864 \\
\hline
\end{tabular}




\subsection{The research population and sample size}

The statistical population of this study was all users of electronic services of the Social Security Organization (Branch 17) on May $2014(\mathrm{~N}=700)$. Thus, the sample size was determined at (e) level of accuracy and equal to 0.05 and at $95 \%$ confidence level. It should be noted that the latter levels were determined in accordance with Table 9-2 in a book titled "research, scholarship and research writing" (Mirzayi, 2009), which was itself adopted from Glenn D. Israel (2008). As such, the sample size was determined as 255 individuals.

\subsection{Sampling method}

Those individuals who were using electronic services of Social Security Organization (Branch 17) on Saturdays, Mondays and Tuesdays in May 2014 were randomly selected to respond to the research questionnaires.

\section{Data analysis}

Processing and analyzing the data is very essential to verify hypotheses in any type of study. Nowadays, the majority of research that relies on data collected from the subject pays special attention to analysis of data as one of the most determining and important parts of any given research. Raw data are processed via statistical techniques and, then, these processed data are placed at the disposal of users. Regarding this study, descriptive statistics were used to characterize samples and linear regression analysis was used to analyze the relationship between the variables.

\subsection{Descriptive statistics}

Regarding the first part of statistical analysis, the statistical distribution has been characterized in terms of gender, age, education, job and the level of using electronic services (Table 2).

Table 2. Descriptive statistics

\begin{tabular}{|l|l|c|c|}
\hline Demographic variable & Description & Frequency & Percentage \\
\hline The total sample size & 373 & & \\
\hline \multirow{2}{*}{ Gender } & Female & 78 & $30.5 \%$ \\
\cline { 2 - 4 } & Male & 177 & $69.5 \%$ \\
\hline \multirow{5}{*}{ Age } & $20-30$ & 25 & $10 \%$ \\
\cline { 2 - 4 } & $31-40$ & 136 & $53 \%$ \\
\cline { 2 - 4 } & 41 and older & 94 & $37 \%$ \\
\hline \multirow{5}{*}{ Job } & Formal employment & 131 & $51.5 \%$ \\
\cline { 2 - 4 } & Informal employment (free) & 83 & $32.5 \%$ \\
\cline { 2 - 4 } & Student & 13 & $5 \%$ \\
\cline { 2 - 4 } & Housekeeper & 28 & $11 \%$ \\
\hline \multirow{5}{*}{ Education } & Diploma and lower & 17 & $7 \%$ \\
\cline { 2 - 4 } & Associate degree & 78 & $31 \%$ \\
\cline { 2 - 4 } & B.A. degree & 95 & $37 \%$ \\
\cline { 2 - 4 } & M.A. and upper & 65 & $25 \%$ \\
\hline
\end{tabular}

\subsection{The analysis of correlation between research variables}

Before the model was examined in terms of structural equations, it was decided to make use of Pearson correlation coefficient to analyze the correlation between the research variables. The results (Table 3 ) showed that there was a significant positive correlation between all dimensions of quality of electronic services (independent variables) and user satisfaction (the dependent variable). The highest correlation was observed between service interaction and user satisfaction $(0.661 \%)$. Also, there was a positive correlation between usability and user satisfaction (0.646\%). In addition, there was a significant positive correlation between information quality and user satisfaction $(0.637 \%)$. 
Table 3. Correlation between variables

\begin{tabular}{|l|c|c|}
\hline Variable & Pearson correlation coefficient & Sig. \\
\hline Usability & 0.646 & 0.001 \\
\hline Information quality & 0.637 & 0.001 \\
\hline Service interaction & 0.661 & 0.001 \\
\hline
\end{tabular}

\subsection{The results of regression analysis}

As seen in stepwise regression analysis (Table 4), three variables of usability, information quality and service interactions have been multiply correlated with user satisfaction. Regarding the order of importance of predictor variables in the stepwise regression analysis, the first step belonged to the multiple correlation coefficient between service interaction and user satisfaction (0.661). The second step belonged to the multiple correlation coefficient between usability and user satisfaction (0.721). The added multiple correlation coefficient for usability was 0.06 . Finally, the third step belonged to the multiple correlation coefficient between information quality and user satisfaction (0.73). The added multiple correlation coefficient for information quality was 0.007 thereof.

In sum, these three variables were able to account for $53.2 \%$ of the variance in user satisfaction in which $43.6 \%$ was related to service interaction, $8.4 \%$ was related to usability and $1.2 \%$ was related to information quality.

Table 4. Correlation coefficients, square of the multiple correlation coefficient, modified correlation coefficient and standard error estimates adjusted for user satisfaction

\begin{tabular}{|c|c|c|c|c|}
\hline $\begin{array}{c}\text { Statistical indexes } \\
\text { Predictor varriabte }\end{array}$ & $\begin{array}{c}\text { Multiple correlation } \\
\text { coefficient }\end{array}$ & $\begin{array}{c}\text { Square of the multiple } \\
\text { correlation coefficient }\end{array}$ & $\begin{array}{c}\text { Modified correlation } \\
\text { coefficient }\end{array}$ & $\begin{array}{c}\text { Estimated } \\
\text { standard error }\end{array}$ \\
\hline Service interaction & 0.661 & 0.436 & 0.434 & 2.56 \\
\hline Usability & 0.721 & 0.52 & 0.516 & 2.37 \\
\hline Information quality & 0.73 & 0.532 & 0.527 & 2.34 \\
\hline
\end{tabular}

As can be seen in Table 5, variance analysis approved the reliability of stepwise regression analysis in predicting users satisfaction ( $F=95.297$ and $P<0.001)$.

Table 5. The analysis of regression variance in predicting user satisfaction

\begin{tabular}{|l|c|c|c|c|c|}
\hline Source of change & Total squares & Df. & Mean squares & F ration & Sig. \\
\hline Regression & 1568.089 & 3 & 522.696 & 95.297 & 0.001 \\
\hline Residual & 1376.719 & 251 & 5.485 & & \\
\hline Total & 2944.808 & 254 & & & \\
\hline
\end{tabular}

As can be seen in Table 6 and regarding the stepwise regression analysis, three variables of service interaction, usability and information quality entered into the regression equation to predict user satisfaction. The service interaction (standard coefficient beta $=0.343$ ), usability (standard coefficient beta $=0.295$ ) and information quality (standard coefficient beta $=0.181$ ) have had a significant predicting power in terms of user satisfaction $(P<0.001)$, respectively. These standard beta coefficients meant that one unit change in the service interaction, usability and information quality led to $0.343,0.295$ and 0.181 units change in these variables in relation to user satisfaction. According to Table 6 , the final regression equation for user satisfaction was as follow:

6.212 (User satisfaction) $=0.143$ (information quality) +0.198 (usability) +0.29 (service interaction).

Table 6. Standard and non-standard regression coefficients for user satisfaction

\begin{tabular}{|c|c|c|c|c|c|}
\hline $\begin{array}{c}\text { Statistical indexes } \\
\text { Variables }\end{array}$ & $\begin{array}{c}\text { Non-standard beta } \\
\text { coefficient }\end{array}$ & $\begin{array}{c}\text { Standard } \\
\text { error }\end{array}$ & $\begin{array}{c}\text { Standard beta } \\
\text { coefficient }\end{array}$ & $\begin{array}{c}\text { T- } \\
\text { value }\end{array}$ & Sig. \\
\hline Constant value & 6.212 & 1.079 & & 5.757 & 0.001 \\
\hline Service interaction & 0.29 & 0.053 & 0.343 & 5.423 & 0.001 \\
\hline Usability & 0.198 & 0.044 & 0.295 & 4.537 & 0.001 \\
\hline Information quality & 0.143 & 0.056 & 0.181 & 2.568 & 0.01 \\
\hline
\end{tabular}




\section{Conclusion}

Regarding the outcome of the first hypothesis of the study, it is indicated that there is a direct relationship between usability and user satisfaction among users of electronic services of the Social Security Organization at 0.95 statistical level. In other words, the component of usability can be used as a determining factor in the field of electronic service quality to affect user satisfaction with the electronic services of the Social Security Organization at 0.95 statistical level. Usability indicates the extent of convenience, ease of access and efficiency of any given website. In general, usability of any given website increases user satisfaction (Jakob Nielsen, 2012).

Regarding the outcome of the second hypothesis of the study, it is indicated that there is a direct relationship between information quality and user satisfaction among users of electronic services of the Social Security Organization at 0.95 statistical level. In other words, the component of information quality can be used as a determining factor in the field of electronic service quality to affect user satisfaction with the electronic services of the Social Security Organization at 0.95 statistical level. Information quality, which includes confidentiality of individuals' information, understandability and usefulness of the information contained on the website, connectivity to webmasters, etc., increases user satisfaction (Mina and Anio, 2005).

Regarding the outcome of the third hypothesis of the study, it is indicated that there is a direct relationship between service interaction and user satisfaction among users of electronic services of the Social Security Organization at 0.95 statistical level. In other words, the component of service interaction can be used as a determining factor in the field of electronic service quality to affect user satisfaction with the electronic services of the Social Security Organization at 0.95 statistical level. If customers receive services in accordance with their expectations, they will be satisfied. When a customer finds that the organization provides high-quality, acceptable and timely services, he/she will decide to repeat his/her act in this regard. Therefore, the interaction of electronic services will increase user satisfaction (Harrison, 1994).

\section{Recommendations}

- The results of this study indicate that the usability of electronic services and user satisfaction are positively correlated. Therefore, it is suggested that organizations adopt necessary strategies and policies to increase the usability of electronic services, including increasing the ease of learning how to work with the website, establishing clear contact with the website, increasing ease of browsing in the website, facilitating use of the website and increasing the attractiveness of website to increase the user satisfaction.

- The results of this study indicate that the information quality of electronic services and user satisfaction are positively correlated. Therefore, it is suggested that organizations increase the quality of information provided, including website information, credibility of website information, timeliness of website information, the connection between website information and its function and ease of understanding information website so that they can implement such a policy in order to attract user satisfaction.

- The results of this study indicate that the service interaction of electronic services and user satisfaction are positively correlated. Therefore, it is suggested that the organization increases its effort to enhance the public profile of website among citizens, the level of transaction security via the website, the security of personal information on the website, the ability to personalize websites so that user satisfaction can be increased thereof.

\section{References}

Anderson, R. E., \& Srinivasan, S. S. (2003). E-Satisfaction and e-Loyalty: A contingency framework. Psychology \& Marketing, 20(2), 123-138.

Bhattacharya, N., Ecker, F., Olsson, P., Schipper, K. (2012a). Direct and mediated associations among earnings quality, information asymmetry, and the cost of equity. The Accounting Review 87, 449-482.

Bhattacharya, N., Hemang, D., Kumar, V. (2012b). Does earnings quality affect information asymmetry. Evidence from trading costs. Contemporary Accounting Research, forthcoming.

Delone, W., \& McLean, E. (2003). Information systems success: The quest for the dependent variable. Information Systems Research, $3(1), 60-95$.

Hejazi, S. M. (2005). Measurement of satisfaction in Ramak Company by fuzzy approach (Master thesis), Shahid Beheshti University, Tehran.

Iran Nejad Parizi, M. (2005). Honoring the customer and providing premier services (fundamental change in the bureacratic system of the country). Journal of Bureacratic Reform, 49. 
Loiacono, T., Watson, R. T., \& Hoodhue, D. L. (2002). WEBQUAL: Measure of website quality. Marketing educators conference: Marketing theory and application, 13, $432-437$.

Mirzayi, K. (2009). Research, scholarship and research writing. Tehran: Jame'e Shenasan Publications.

Molavi, Z. (2009). A survey of relationship between electronic services quality and electronic satisfaction in banking system; the case of central branch of Agricultural Bank of Tabriz (master thesis), Islamic Azad University (Bonab Branch).

Parasuraman, A., Zeithaml, V. A., \& Malhotra, A. (2005). E-S-QUAL: A multiple-item scale for assessing electronic service quality. Journal of Service Research, 7 (3), 213-233.

Shankar, V., Smith, A. K., \& Rangaswamy, A. (2003). Customer satisfaction and loyalty in online and offline environments. International Journal of Research in Marketing, 20, 153-175.

Zeithaml, Valarie A, A. Parasuraman and Arvind Malhotra (2002), "Service Quality Delivery through Web Sites: A Critical Review of Extant Knowledge". Journal of the Academy of Marketing Science, 30, 4, 362-375.

Zhang, X., \& Prybutok, R. (2005) A consumer perspective of e-Service quality. IEEE Transactions on Engineering Management, 52(4), 461-477. 